\title{
Autophagy, Stress, and Cancer Metabolism: What Doesn't Kill You Makes You Stronger
}

\author{
R. MATHew ${ }^{1,2,3}$ AND E. White ${ }^{1,3,4}$ \\ ${ }^{1}$ The Cancer Institute of New Jersey, New Brunswick, New Jersey 08903 \\ ${ }^{2}$ Laboratory, Princeton University, Lewis-Sigler Institute for Integrative Genomics, 241 \\ Carl Icahn, Princeton, New Jersey 08544 \\ ${ }^{3}$ University of Medicine and Dentistry of New Jersey, Robert Wood Johnson Medical School, \\ Piscataway, New Jersey 08854 \\ ${ }^{4}$ Department of Molecular Biology and Biochemistry, Rutgers University, Piscataway, New Jersey 08854 \\ Correspondence: mathewro@umdnj.edu
}

\begin{abstract}
Altered metabolism is a hallmark of cancer. Oncogenic events that lead to cancerous states reorganize metabolic pathways to increase nutrient uptake, which promotes biosynthetic capabilities and cell-autonomous behavior. Increased biosynthesis dictates metabolic demand for ATP, building blocks, and reducing equivalents, rendering cancer cells metabolically in a perpetually hungry state. Moreover, most chemotherapy agents induce acute metabolic stress that cancer cells must overcome for their survival. These metabolic stress cues in cancer cells can activate and cause dependence on the self-cannibalization mechanism of macroautophagy (autophagy hereafter) for the lysosomal turnover and recycling of organelles and proteins for energy and stress survival. For example, activating mutations in Ras or Ras-effector pathways induce autophagy, and cancer cell lines with Ras activation show elevated levels of basal autophagy that is essential for starvation survival and tumor growth. The metabolic implications of this are profound and multifaceted. First, autophagy-mediated degradation and recycling of cellular substrates can support metabolism and promote survival and tumor growth. Second, acute autophagy activation in response to cancer therapy can potentially lead to refractory tumors resistant to conventional chemotherapy. For example, a specific form of autophagy that targets mitochondria (mitophagy) may also function to promote cell survival by the clearance of damaged mitochondria that are potential sources of reactive oxygen species (ROS). These point to the possibility that autophagy is a unique metabolic need, important for survival as well as therapy resistance in cancer cells. Targeting autophagy in single-agent therapy to sensitize aggressive cancers that are dependent on autophagy for survival or in combination with therapeutic agents that induce autophagy as a resistance mechanism may be an effective therapeutic strategy to treat cancer.
\end{abstract}

\section{CANCER IS A METABOLIC DISEASE}

Cancer cells harbor unique, growth-permissive genetic alterations that deregulate the control of cell growth and proliferation. However, accumulating evidence in recent years also links these oncogenic lesions to altered cellular metabolism, establishing a direct relationship between the two. The phosphoinositide 3-kinase (PI3K) pathway, the master regulator of cell growth and proliferation, is one of the most commonly mutated oncogenic pathways in human cancers. Deregulation of the downstream kinase, the mammalian target of rapamycin (mTORC1), directly or indirectly impacts metabolic functions such as glycolysis, the pentose phosphate pathway (PPP), mitochondrial metabolism, and lipid synthesis (Zoncu et al. 2011). Importantly, mTORC1 is the convergence point of the two major oncogenic pathways under the growth-factor-dependent activation of the receptor tyrosine kinases (RTKs), the PI3K, and the mitogen activated protein kinase (MAPK) pathways frequently altered in human cancers.

Cancer cells harbor frequent activating mutations in RTKs, in PI3K (p110a PI3K subunit, AKT, and PDK1), and the MAPK (K-Ras, H-Ras, N-Ras, and B-Raf) pathway components that positively regulate mTORC1 signaling (Zoncu et al. 2011). Also common are lossof-function mutations in tumor suppressors such as phosphatase and tensin homolog (PTEN) mutated in chromosome 10, tuberous sclerosis complex (TSC1 and TSC2), and neurofibromitosis (NF1 and NF2), all of which negatively regulate mTORC1 signaling (Zoncu et al. 2011). Aberrant mTORC1 signaling is detected at very high frequencies among the most common human cancers (Menon and Manning 2008). In addition, another commonly mutated tumor-suppressor gene, liver kinase B1 (LKB1), is required for the activation of AMP kinase (AMPK), an inhibitor of mTORC1 in response to energy stress, leading to constitutive activation of mTORC1 signaling (Shackelford and Shaw 2009). The unique metabolism found in human cancers is, to a large extent, a consequence of this deregulation of mTORC1 and its potential impact on the bioenergetic and anabolic demands of rapidly proliferating cancer cells. Additionally, $\mathrm{Akt} / \mathrm{PKB}$, an upstream regulator of $\mathrm{mTORC} 1$, promotes glycolysis (through GLUT4 translocation to the plasma membrane, hypoxia inducible factor $[\mathrm{Hif}-1 \alpha]$-mediated activation of the glucose transporter, GLUT1, and 6-phosphofructo-2-kinase ([PFK2] [Manning and Cantley 2007]) 
and fatty acid synthesis (through phosphorylation of ATP citrate lyase ([ACL] [Manning and Cantley 2007]). Activation of mTORC1 also up-regulates glycolysis through up-regulation of the oncogenic transcription factors Myc and Hif- $1 \alpha$ through expression of genes encoding glycolytic enzymes (Iyer et al. 1998). mTORC1 promotes the Hif- $1 \alpha$-dependent up-regulation of GLUT1, hexokinase isoforms HK1 and HK2 (catalyzing the initial step of glycolysis), lactate dehydrogenase LDH1 (that promotes conversion of pyruvate to lactate), and pyruvate dehydrogenase kinase 1 (PDK1, which inhibits the conversion of pyruvate to acetyl-coenzyme A [CoA] by inhibiting pyruvate dehydrogenase [PDH] [Semenza 2010a]), which are predicted to compromise mitochondrial oxidative metabolism in favor of glycolysis. However, mTORC1 appears to have a more complex role in mitochondrial metabolism because mTORC1 activation promotes mitochondrial biogenesis and oxidative metabolism in some settings (Schieke et al. 2006; Cunningham et al. 2007) and mitochondrial function is important for cancer cell maintenance.

Biosynthetic needs of cancer cells are not limited to carbon from glucose; they also require nitrogen, which is provided by glutamine and other amino acids through anaplerotic reactions in the mitochondria, and transamination reactions that take place in the cytosol. Thus, the Warburg effect is insufficient to sustain the growth and proliferation of cancers, which need a robust supply of reduced nitrogen to produce nucleotides and nonessential amino acids. Glutamine, the most abundant free amino acid in the serum, aids in the transport of reduced nitrogen through the bloodstream. Proliferating tumor cells also use carbon units from glutamine to maintain pools of tricarboxylic acid (TCA) cycle intermediates and its nitrogen to produce nonessential amino acids, hexosamine, and nucleotides. Consistently, concurrent aerobic glycolysis and oxidative phosphorylation occur in experimental systems with activated oncogenes, with glutamine playing an important role in oxidative phosphorylation and anaplerosis, especially when glucose is limiting. Recent findings suggest that glutamine is also used to produce citrate for lipid synthesis, via reductive carboxylation, in cancers with mutational inactivation of the electron transport chain and oxidative phosphorylation (Mullen et al. 2012), thus establishing the importance of glutamine and mitochondria even in cancers with impaired oxidative phosphorylation.

Glutaminolysis can also provide nicotinamide adenine dinucleotide phosphate-oxidase (NADPH), which is necessary for lipid and nucleotide biosynthesis. mTORC1, through the activation of c-myc, an oncogene highly expressed in several human cancers, up-regulates glutaminolysis and NADPH and glutathione (GSH) production (Wise et al. 2008; Gao et al. 2009). Consistent with this central role for mTORC1 in mitochondrial metabolism, inhibition of mTORC1 by rapamycin reduces mitochondrial respiration (Ramanathan and Schreiber 2009), and genetic ablation of mTORC1 in skeletal muscle impairs mitochondrial function (Bentzinger et al. 2008), suggesting a positive role for the mTOR pathway in mitochondrial metabolism.
Interaction of signaling cascades and cancer metabolism is a two-way street, with one feeding the other. Mutational alterations in cancer cells have the power to not only change the regulatory state but to impose alterations in the metabolic as well as the epigenetic state of cancer cells. For example, in glioblastoma cells, missense mutations in the metabolic enzyme isocitrate dehydrogenase (IDH1/2) (Parsons et al. 2008; Yan et al. 2009) influence the metabolic state of the cells by catalytically converting $\alpha$-ketoglutarate $(\alpha-\mathrm{KG})$ to the oncometabolite 2-hydroxyglutarate (2-HG) in an NADPH-dependent manner (Dang et al. 2009). The consequences of such metabolic hijacking are profound. Replacement of $\alpha-\mathrm{KG}$ with 2-HG alters the metabolic pathways that use $\alpha-K G$ as an essential cofactor but are inhibited by 2-HG. Examples of these are dioxygenase enzymes such as prolyl hydroxylases involved in regulation of gene expression and metabolism under hypoxia through regulation of Hif-1 $\alpha$ (Bruick and McKnight 2001; Epstein et al. 2001) and those involved in histone demethylation (Hou and Yu 2010). The TCA cycle enzymes, succinate dehydrogenase (SDH; also a member of mitochondrial respiratory chain complex II) and fumarate hydratase (FH) have important tumor suppressor roles, and LOF mutations in these genes cause aberrant accumulation in succinate and fumarate. Accumulation in these TCA metabolites, as with 2-HG, leads to inhibition of prolyl hydroxylases, stabilizing Hif- $1 \alpha$, and constitutive activation of the hypoxia response, leading to transcriptional up-regulation of glycolysis, as observed with von Hippel-Lindau (VHL) gene deletions (Maxwell et al. 1999; Ohh et al. 2000). Indeed, mutations in FH (Isaacs et al. 2005) and SDH (Pollard et al. 2005; Frezza et al. 2011) are observed in renal cancers, paragangliomas, and pheochromocytomas. Additionally, mitochondrial reactive oxygen species (ROS) generated from complex III of the electron transport chain (ETC) also regulate hypoxic activation of Hif- $1 \alpha$ (Klimova and Chandel 2008) and hypoxia-responsive gene expression. Thus, the metabolic state of a cell can also control its regulatory state, indicating a dynamic and reciprocal relationship between the two.

\section{CANCER CELLS ARE PERPETUALLY NUTRIENT HUNGRY}

One of the consequences of this reciprocal relationship between metabolism and gene regulation is that oncogene activation can lead to metabolic crisis and increased energy demand, altering gene expression. Cancer cell proliferation is a metabolically expensive process. Increased biosynthetic needs dictate high demand for ATP, building blocks, and reducing equivalents, rendering cancer cells nutritionally in a perpetually hungry state. Stress is also a common feature of tumors, which have hypoxic regions depleted in oxygen and probably also in growth factors and nutrients (Folkman 2007). The nutritionally hungry state of cancers in vivo can arise due to (1) increased need for ATP and anabolic substrates for biosynthetic processes and (2) inaccessibility to nutrients due to abnormal 
organization and structure in tumor vasculature, resulting in decreased blood flow (Jain 1988), and focal leaks that compromise the blood perfusion in tumors (Fukumura et al. 2010). This heterogeneity in vasculature creates hypoxic regions that are refractory to chemotherapy and insensitive to radiation (Fukumura et al. 2010).

Under hypoxic conditions, mitochondrial complex III acts as an oxygen sensor, releasing ROS into the cytosol as signaling molecules that stabilize Hif- $1 \alpha$ to induce hypoxic gene expression (Chandel et al. 2000; Klimova and Chandel 2008), promoting nutrient uptake. Consistent with this, cancer cells show high levels of Hif-1 $\alpha$ and Hif-2 $\alpha$ (Zhong et al. 1999; Talks et al. 2000) and increased sensitivity to nutrients and amino acids. Hypoxic tumor cells activate the stress-survival pathway of autophagy when subjected to stress in vitro and in tumors in vivo (Degenhardt et al. 2006; Mathew et al. 2007b). In support of this, we and other investigators have observed that cancer cells with tumorigenic mutations in Ras are energetically compromised under starvation without autophagy to meet their bioenergetic needs. Despite relatively high basal autophagy, Ras limits the ability to induce further autophagy, which can compromise stress adaptation (Guo et al. 2011; Yang et al. 2011). Human cancer cells with high Ras expression also show elevated basal autophagy, which is essential for starvation survival under metabolic stress (Guo et al. 2011; Lock et al. 2011). Thus, oncogene activation represents a major mechanism for metabolic stress in cancers, which in turn activates metabolic recycling and adaptation pathways that enable cellular nutrient uptake and survival.

\section{METABOLIC STRESS INDUCES THE CATABOLIC PATHWAY OF AUTOPHAGY, ENABLING SURVIVAL}

Autophagy is a self-cannibalization process robustly activated in response to metabolic stress that targets and recycles toxic intracellular cargo that includes damaged proteins and organelles in the lysosomes (Mizushima 2010). Stress-responsive autophagy activation is tightly coupled with nutrient availability under the regulation of PI3K and AMPK pathways, the two major energy-sensing pathways of the cell. Induction of autophagy requires activation of the Unc-51-like kinase (ULK) complex (ULK1 and ULK2, Atg13, and the focal adhesion kinase family interacting protein, FIP200) (Hosokawa et al. 2009) that initiates the formation of preautophagosomal structures (PAS) called phagophores. Under nutrient-replete conditions, mTORC1 is activated, which keeps autophagy suppressed through inactivation of the ULK complex, preventing the nucleation of phagophores (Hosokawa et al. 2009). Nutrient signals also activate the Ras/MAPK pathway, which phosphorylates LKB1, inhibiting its ability to bind and activate AMPK, a starvation sensor and autophagy activator (Zheng et al. 2009). Under metabolic stress, mTORC1 kinase activity is inhibited, de-repressing the ULK complex, leading to its activation and autophagy induction (Neufeld 2010). A simultaneous increase in the AMP/ATP ratio leads to the activation of AMPK by the LKB1/STRAD/MO25 complex (Kuma and Mizushima 2010; Neufeld 2010), which activates autophagy by ULK1 phosphorylation (Egan et al. 2011), as well as through inhibition of mTORC1 (Gwinn et al. 2008). These pathways integrate the coordinated regulation of growth control signals with nutrient availability and catabolism. Although starvation-induced autophagy is mainly regulated by mTORC1 signaling, autophagy is also regulated through mTORC1-independent mechanisms. For example, ammonia derived from glutaminolysis induces autophagy in an mTORC1 (Eng et al. 2010) and ULK1/2 (Cheong et al. 2011) independent manner.

The primary role of autophagy is promoting stress adaptation and starvation survival, which is well established by elegant observations in multiple organism and genetic backgrounds. Yeast cells defective for autophagy fail to survive starvation and show signs of amino acid depletion and defects in energy metabolism (Onodera and Ohsumi 2005; Suzuki et al. 2011). Similarly, in mammalian systems, impaired autophagy owing to deficiency in essential autophagy genes $\operatorname{atg} 3$, atg5, atg7, or beclin 1 impairs stress survival (Mizushima and Komatsu 2011). Newborn pups with maternally inherited autophagy proteins, but deficient for $\operatorname{atg} 5, \operatorname{atg} 7$, and $\operatorname{atg} 3$, fail to survive neonatal starvation and display signs of bioenergetic impairment (Kuma et al. 2004; Komatsu et al. 2005; Sou et al. 2008). Autophagy also plays an important role in tumor cell survival to metabolic stress in vitro as well as in tumors in vivo. In response to acute starvation, cancer cells robustly induce autophagy, which is required for their survival of metabolic stress (Lum et al. 2005; Degenhardt et al. 2006; Karantza-Wadsworth et al. 2007; Mathew et al. 2007b). During prolonged metabolic stress, autophagy-competent tumor cells use autophagy to maintain a state of dormancy during which they are viable and capable of resuming proliferation upon restoration of nutrients (Degenhardt et al. 2006; Mathew et al. 2007a). Defects in essential autophagy genes impair this ability and autophagy-defective cells fail to survive metabolic stress, underscoring the importance of autophagy in this setting. Autophagy is also activated in tumor cells in vivo, where it colocalizes to regions of metabolic stress, suggesting that autophagy is activated in tumors as a protective mechanism against metabolic deficiency (Degenhardt et al. 2006).

\section{ONCOGENE ACTIVATION CAUSES DEPENDENCE ON AUTOPHAGY FOR TUMOR CELL SURVIVAL}

Oncogenic events that drive cell proliferation rewire cellular metabolism and, in doing so, create profound metabolic stress owing to metabolic reprogramming and elevated metabolic demand. Aggressive tumors that harbor such mutations also show signs of this demand by robustly activating autophagy to deal with this metabolic crisis. This is consistent with elevated basal autophagy and mitophagy (a specific form of autophagy that targets mitochondria), even under normal culture conditions, observed in tumor cells with activating mutations in Ras or Ras-effector pathways. Defects in autophagy 
compromise survival of these cells in starvation and block tumor growth in allograft models (Guo et al. 2011), indicating that these cells are addicted to autophagy for their survival under stress.

Autophagy is similarly activated and is required for Ras-driven pancreatic cancers (Yang et al. 2011) and $B C R$ - $A b l$-mediated leukemogenesis (Altman et al. 2011). Human cancer cell lines with endogenous K-Ras mutations activate autophagy upon extracellular matrix (ECM) detachment, which protects them from detachment-induced cell death (anoikis) (Fung et al. 2008). The possibility that oncogene activation and ensuing metabolic stress cues in cancer cells can activate and cause dependence on autophagy for energy and stress survival has raised interesting questions. For example, how does Ras promote autophagy addiction? One possibility is that Ras activates autophagy by direct (Kalas et al. 2011) or indirect Hif-1 $\alpha$-mediated activation of BNIP3, an inducer of autophagy. Additionally, it is also possible that increased glutaminolysis and ammonia production triggers autophagy induction under these conditions (Eng et al. 2010). The autophagy-mediated stress response mechanism may be particularly important in cancer cells to limit cell death and tissue inflammation, to recycle toxic damaged proteins and organelles, and to provide energy and metabolic substrates. Autophagy also triggers clearance of damaged mitochondria (mitophagy), which are potential sources of ROS involved in activation of cell death via ROS-induced necrosis (Pourova et al. 2010). Understanding the mechanism for autophagy addiction will assist in our efforts to therapeutically target this important survival mechanism exploited by cancer cells.

\section{TOWARD A MECHANISM FOR AUTOPHAGY ADDICTION: AUTOPHAGY SUPPORTS METABOLISM}

The reason why cancer cells promote autophagy basally and under pharmacologically induced stress is largely speculative at this juncture. The exact mechanism of autophagy addiction probably involves more than one process, but autophagy-mediated recycling of macromolecules and organelles to fuel mitochondrial metabolism under starvation is the most compelling possibility. This stems from recent findings that autophagy drives Rasdriven tumor growth by supporting oxidative metabolism (Guo et al. 2011; Yang et al. 2011). The role of autophagy in supporting mitochondrial metabolism may be twofold: Autophagy (1) maintains a healthy mitochondrial pool by elimination of depolarized mitochondria through mitophagy (Youle and Narendra 2011) and (2) ensures an uninterrupted supply of mitochondrial substrates through catabolic degradation of macromolecules under starvation (Mathew and White 2011). Consistent with this, Ras-expressing cells that are defective for autophagy pathway, either by deficiency in autophagosome formation or by cargo delivery, causes accumulation of abnormal mitochondria with a reduced capacity for oxygen consumption (Guo et al. 2011). Additionally, Ras activation causes specific depletion of the mitochondrial TCA metabolites citrate and isocitrate and reduced mitochondrial oxidative phosphorylation, indicative of mitochondrial impairment (Guo et al. 2011). Thus autophagy is necessary for mitochondrial metabolic function when Ras is activated.

Autophagy may also limit toxicity due to mitochondrial ROS through mitophagy, wherein depolarized mitochondria are eliminated through lysosomal degradation (Wild and Dikic 2010). Failed mitochondrial quality control may be compounded by substrate limitation owing to autophagy defects, especially under metabolic stress. Additionally, impaired mitochondrial metabolism and consequent impairment in bioenergetics may potentially select for increased glycolysis, contributing to the Warburg effect. Thus, failure of mitochondrial quality control in autophagy-defective cells may be an alternative means of achieving less dependence on oxidative metabolism.

Depletion in the levels of citrate in Ras-expressing cells under stress may have profound implications in cancer metabolism, given its crucial role in the synthesis of new lipids. Pyruvate, the major product of glycolysis, enters the TCA cycle and produces acetyl-CoA to generate citrate within the mitochondria. Mitochondrially produced citrate is then exported into the cytoplasm for fatty acid synthesis. Ras activation is known to rewire cellular metabolism to diminish acetyl-CoA synthesis in mitochondria, thereby potentially inhibiting the mitochondrial metabolism. For example, Ras activates $\mathrm{LDH}$, an enzyme that converts pyruvate into excreted lactate, limiting mitochondrial pyruvate availability. Additionally, Ras activates Hif- $1 \alpha$ and its downstream target, PDK1, which is an inhibitor of $\mathrm{PDH}$, the enzyme responsible for the conversion of pyruvate into acetyl-CoA in the mitochondria (Chun et al. 2010; Semenza 2010b). Raf/Erk activation can potentially inhibit LKB1, blocking AMPK activation and the utilization of lipid stores through $\beta$ oxidation. Thus, Ras increases the dependence on autophagy to provide substrates such as amino acids and fatty acids for acetyl-CoA biosynthesis by curtailing acetylCoA production (Fig. 1). Additionally Ras may shorten the mitochondrial life span, through substrate limitation further exacerbated by Ras-dependent Hif- $1 \alpha$ activation that impairs mitochondrial biogenesis (Zhang et al. 2007). Consistent with this, Ras causes accumulation of abnormal mitochondria, impairment in mitochondria oxidative respiration, and cellular energy charge (Guo et al. 2011). Additionally, the activated Ras/MAPK pathway activates PI3K pathways, which causes transcriptional down-regulation of carnitine palmitoyltransferase $1 \mathrm{~A}$ (Cptla) (Deberardinis et al. 2006), the rate-limiting enzyme for mitochondrial uptake and utilization of fatty acids by $\beta$-oxidation. One possible consequence of this inhibition of $\beta$-oxidation, which shuts down an important source of substrates for mitochondria, is an increased dependence of cancer cells on autophagy, which provides amino acids as mitochondrial substrates through protein degradation.

Thus, it is possible that the major role of autophagy under this circumstance is to compensate for the metabolic reprogramming imposed by Ras expression primarily 


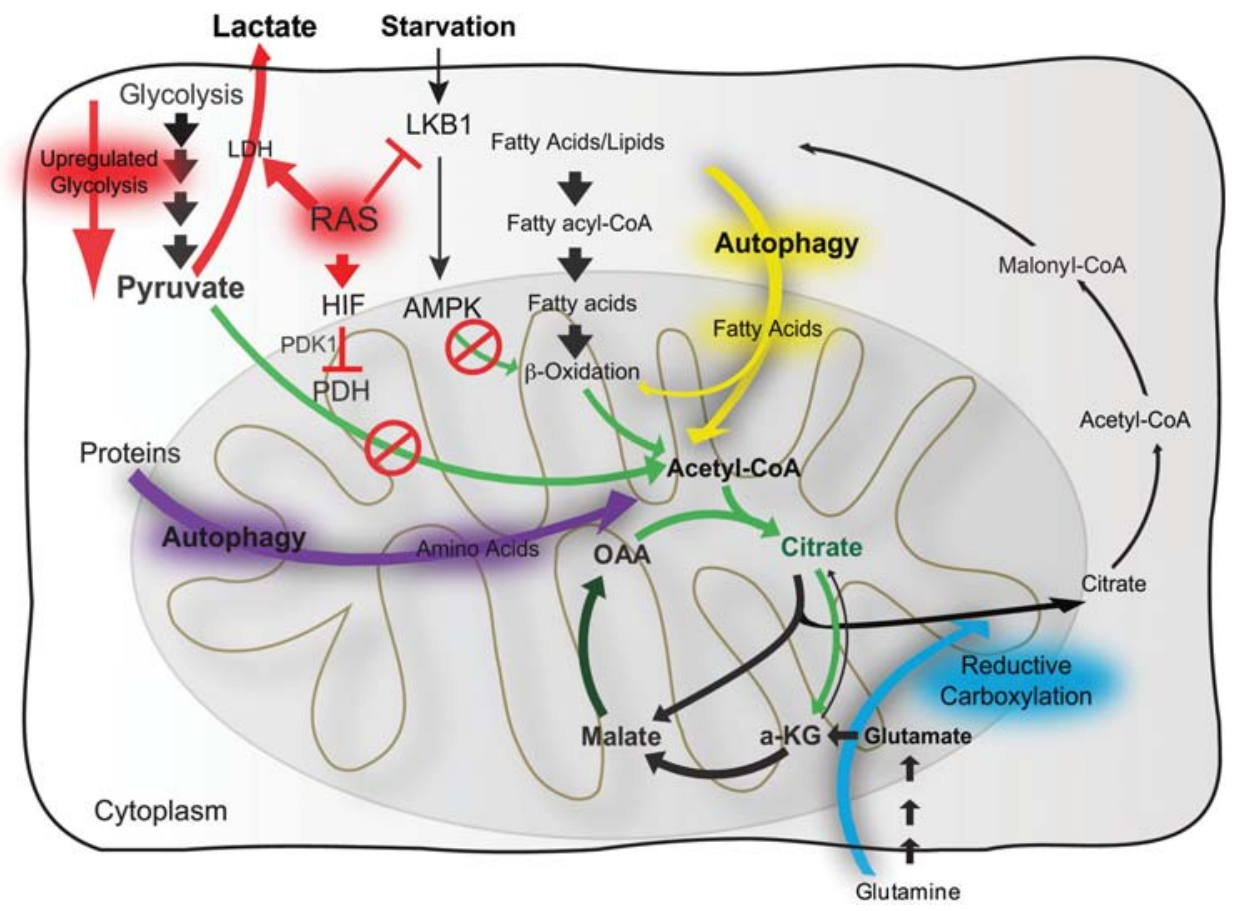

Figure 1. Mechanisms of autophagy addiction in Ras-driven cancers. Activated forms of Ras diminish the acetyl-coenzyme A (CoA) pool (green arrow) by activating lactate dehydrogenase (LDH), which converts pyruvate to lactate (red arrow), by activating Hif-1 $\alpha$, inhibiting pyruvate dehydrogenase (PDH) and converting pyruvate to acetyl-CoA (red arrow), and also by inhibiting LKB1, blocking AMP-kinase (AMPK) and $\beta$-oxidation (red arrow). Defects in autophagy result in reduced citrate levels, impaired tricarboxylic acid (TCA) cycle function, and loss of mitochondrial respiration (Guo et al. 2011). Autophagy can compensate for this metabolic reprogramming by Ras by providing amino acid and fatty acid substrates from protein degradation that can produce acetyl-CoA (purple and yellow arrows, respectively). Tumor cells may also be able to compensate for autophagy impairment by up-regulating glycolysis (red arrow) or reductive carboxylation of $\alpha-\mathrm{KG}$ from glutamine (blue arrows). OAA, Oxaloacetate.

by degrading proteins providing free amino acids, especially glutamine to anaplerotic replenishment of acetylCoA (Fig. 2). Ammonia production in glutaminolysis may be important for cells to balance extra nitrogens and to further induce autophagy, amplifying the survival signal. Thus, autophagy may cooperate with oncogene activation and increased nutrient uptake, to promote macromolecular biosynthesis to support proliferation. Amino acids can enter the central carbon metabolism as pyruvate, acetyl-CoA, $\alpha$-ketoglutarate $(\alpha-K G)$, and oxaloacetate (Fig. 2) (OAA). If this model is true, Rasexpressing autophagy-defective cells will show significantly reduced protein degradation and free amino acid levels under starvation, coincident with depletion in

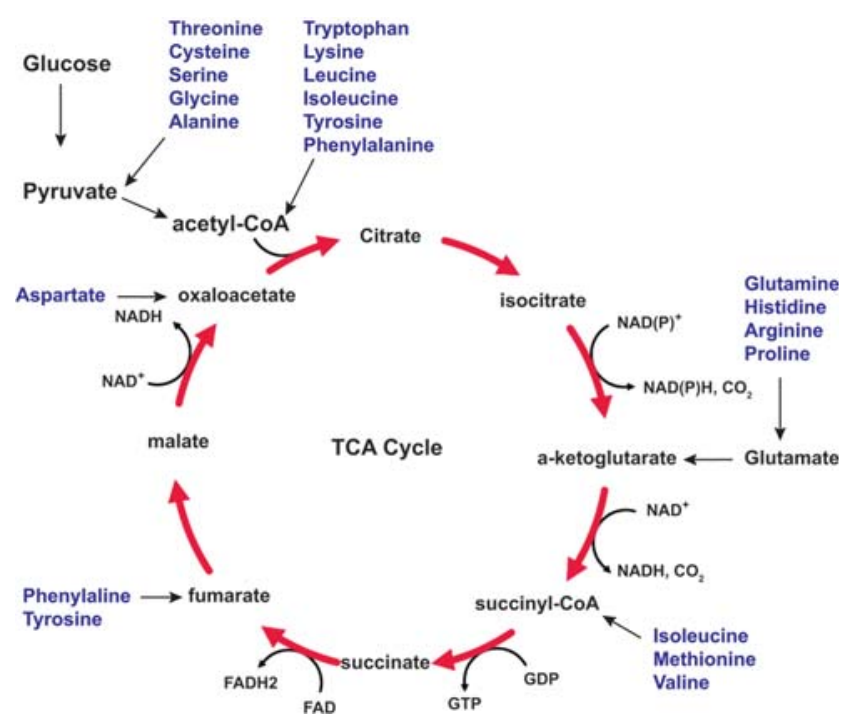

Figure 2. Free amino acids supplement TCA cycle through anaplerosis. Free amino acids from autophagymediated degradation of proteins (shown in purple) can enter the TCA cycle (anaplerosis) at various points to replenish TCA metabolites and support mitochondrial oxidative metabolism. 
energy and biosynthetic intermediates such as citrate seen in Ras-driven tumors (Guo et al. 2011). Identification of these autophagy substrates will reveal potential new targets to exploit autophagy addiction and unique metabolic dependencies of oncogene-driven cancers, which are often associated with poor prognosis.

\section{AUTOPHAGY AS A RESISTANCE MECHANISM IN CANCER: THERAPEUTIC IMPLICATIONS}

One important consequence of autophagy-mediated cell survival under stress is the possibility that cancer cells can activate autophagy to resist the impact of chemotherapy and radiation. Most chemotherapy agents induce acute metabolic stress that cancer cells must overcome for their survival. Indeed, most cancer therapeutics acutely activate autophagy, either directly by modulating signaling pathways that control autophagy in the case of many targeted therapies (e.g., mTOR inhibitors) or indirectly as in the case of cytotoxic therapy. Everything that we know so far about autophagy-mediated stress adaptation suggests that autophagy may be this survival mechanism, potentially leading to cells that survive chemotherapy. One dangerous consequence is that acute autophagy activation in response to chemotherapy can lead to tumors resistant to conventional chemotherapy.

Autophagy may also promote therapy resistance through its possible role in preventing cell death through pathways that are induced by cytotoxic levels of ROS. Consistent with this role, ROS induces autophagy (Bhogal et al. 2012), and autophagy mitigates the production and toxic side effects of ROS (Mathew et al. 2009) under stress, which may positively influence tumor resistance. Thus, either through supporting metabolism directly or by limiting cell death pathways, autophagy may have a pro-survival role in aggressive cancers, leading to therapy resistance. In this connection, inhibiting autophagy may be an attractive therapeutic strategy in established, oncogene-driven tumors known to have poor prognosis. There are several clinical trials using the lysomotropic agent hydroxychloroquine to inhibit autophagy in human tumors (White and DiPaola 2009; Amaravadi et al. 2011). However, major limitations are target specificity and the ability to achieve levels that completely inhibit autophagy. Therefore, identification of other targets more specific to the unique metabolism exhibited by autophagyaddicted cancer cells will be highly desirable. Moreover, the ability to evaluate and monitor the progress of autophagy inhibition during chemotherapy is needed. Identifying markers for an in vivo activation and flux of autophagy process will greatly help in this regard.

\section{CONCLUSION}

Autophagy may be an important stress survival mechanism in response to nutritient limitation, oncogene activation, and therapeutic insult that promote tumor dormancy and therapy resistance. However, on a positive note, this unique metabolic need might also represent a therapeutic opportunity to enhance therapeutic efficacy. Targeting autophagy in single-agent therapy to sensitize aggressive cancers that are dependent on autophagy for survival or in combination with therapeutic agents that induce autophagy as a resistance mechanism may be an effective therapeutic strategy. A better mechanistic understanding of how autophagy modulates cell metabolism and death signaling under therapeutic stress and how this impacts treatment response will help in developing better therapeutic strategies.

\section{ACKNOWLEDGMENTS}

We thank the members of Joshua D. Rabinowitz's laboratory at the Lewis-Sigler Institute for Integrative Genomics, Princeton University, and the White laboratory for comments and helpful discussions. E.W. acknowledges support from the National Institutes of Health (R37 CA53370, RO1 CA130893, RC1 CA147961), and the, Department of Defense (W81XWH06-1-0514 and W81XWH05).

\section{REFERENCES}

Altman BJ, Jacobs SR, Mason EF, Michalek RD, MacIntyre AN, Coloff JL, Ilkayeva O, Jia W, He YW, Rathmell JC. 2011. Autophagy is essential to suppress cell stress and to allow BCR-Abl-mediated leukemogenesis. Oncogene 30: 18551867.

Amaravadi RK, Lippincott-Schwartz J, Yin XM, Weiss WA, Takebe N, Timmer W, DiPaola RS, Lotze MT, White E. 2011. Principles and current strategies for targeting autophagy for cancer treatment. Clin Cancer Res 17: 654-666.

Bentzinger CF, Romanino K, Cloetta D, Lin S, Mascarenhas JB, Oliveri F, Xia J, Casanova E, Costa CF, Brink M, et al. 2008. Skeletal muscle-specific ablation of raptor, but not of rictor, causes metabolic changes and results in muscle dystrophy. Cell Metab 8: 411-424.

Bhogal RH, Weston CJ, Curbishley SM, Adams DH, Afford SC. 2012. Autophagy: A cyto-protective mechanism which prevents primary human hepatocyte apoptosis during oxidative stress. Autophagy 8. [Epub ahead of print.]

Bruick RK, McKnight SL. 2001. A conserved family of prolyl4-hydroxylases that modify HIF. Science 294: 1337-1340.

Chandel NS, McClintock DS, Feliciano CE, Wood TM, Melendez JA, Rodriguez AM, Schumacker PT. 2000. Reactive oxygen species generated at mitochondrial complex III stabilize hypoxia-inducible factor- $1 \alpha$ during hypoxia: A mechanism of $\mathrm{O}_{2}$ sensing. J Biol Chem 275: 25130-25138.

Cheong H, Lindsten T, Wu J, Lu C, Thompson CB. 2011. Ammonia-induced autophagy is independent of ULK1/ULK2 kinases. Proc Natl Acad Sci 108: 11121-11126.

Chun SY, Johnson C, Washburn JG, Cruz-Correa MR, Dang DT, Dang LH. 2010. Oncogenic KRAS modulates mitochondrial metabolism in human colon cancer cells by inducing HIF-1 $\alpha$ and HIF-2 $\alpha$ target genes. Mol Cancer 9: 293.

Cunningham JT, Rodgers JT, Arlow DH, Vazquez F, Mootha VK, Puigserver P. 2007. mTOR controls mitochondrial oxidative function through a YY1-PGC-1 $\alpha$ transcriptional complex. Nature 450: 736-740.

Dang L, White DW, Gross S, Bennett BD, Bittinger MA, Driggers EM, Fantin VR, Jang HG, Jin S, Keenan MC, et al. 2009. Cancer-associated IDH1 mutations produce 2-hydroxyglutarate. Nature 462: 739-744.

Deberardinis RJ, Lum JJ, Thompson CB. 2006. Phosphatidylinositol 3-kinase-dependent modulation of carnitine palmitoyltransferase $1 \mathrm{~A}$ expression regulates lipid metabolism 
during hematopoietic cell growth. J Biol Chem 281: 37372 37380 .

Degenhardt K, Mathew R, Beaudoin B, Bray K, Anderson D, Chen G, Mukherjee C, Shi Y, Gelinas C, Fan Y, et al. 2006. Autophagy promotes tumor cell survival and restricts necrosis, inflammation, and tumorigenesis. Cancer Cell 10: $51-64$.

Egan DF, Shackelford DB, Mihaylova MM, Gelino S, Kohnz RA, Mair W, Vasquez DS, Joshi A, Gwinn DM, Taylor R, et al. 2011. Phosphorylation of ULK1 (hATG1) by AMPactivated protein kinase connects energy sensing to mitophagy. Science 331: 456-461.

Eng CH, Yu K, Lucas J, White E, Abraham RT. 2010. Ammonia derived from glutaminolysis is a diffusible regulator of autophagy. Sci Signal 3: ra31.

Epstein AC, Gleadle JM, McNeill LA, Hewitson KS, O'Rourke J, Mole DR, Mukherji M, Metzen E, Wilson MI, Dhanda A, et al. 2001. C. elegans EGL-9 and mammalian homologs define a family of dioxygenases that regulate HIF by prolyl hydroxylation. Cell 107: 43-54.

Folkman J. 2007. Angiogenesis: An organizing principle for drug discovery? Nat Rev Drug Discov 6: 273-286.

Frezza C, Pollard PJ, Gottlieb E. 2011. Inborn and acquired metabolic defects in cancer. J Mol Med 89: 213-220.

Fukumura D, Duda DG, Munn LL, Jain RK. 2010. Tumor microvasculature and microenvironment: Novel insights through intravital imaging in pre-clinical models. Microcirculation 17: 206-225.

Fung C, Lock R, Gao S, Salas E, Debnath J. 2008. Induction of autophagy during extracellular matrix detachment promotes cell survival. Mol Biol Cell 19: 797-806.

Gao P, Tchernyshyov I, Chang TC, Lee YS, Kita K, Ochi T, Zeller KI, De Marzo AM, Van Eyk JE, Mendell JT, et al. 2009. c-Myc suppression of miR-23a/b enhances mitochondrial glutaminase expression and glutamine metabolism. $\mathrm{Na}$ ture 458: 762-765.

Guo JY, Chen HY, Mathew R, Fan J, Strohecker AM, KarsliUzunbas G, Kamphorst JJ, Chen G, Lemons JM, Karantza V, et al. 2011. Activated Ras requires autophagy to maintain oxidative metabolism and tumorigenesis. Genes Dev 25: 460 470.

Gwinn DM, Shackelford DB, Egan DF, Mihaylova MM, Mery A, Vasquez DS, Turk BE, Shaw RJ. 2008. AMPK phosphorylation of raptor mediates a metabolic checkpoint. Mol Cell 30: $214-226$.

Hosokawa N, Sasaki T, Iemura S, Natsume T, Hara T, Mizushima N. 2009. Atg101, a novel mammalian autophagy protein interacting with Atg13. Autophagy 5: 973-979.

Hou H, Yu H. 2010. Structural insights into histone lysine demethylation. Curr Opin Struct Biol 20: 739-748.

Isaacs JS, Jung YJ, Mole DR, Lee S, Torres-Cabala C, Chung YL, Merino M, Trepel J, Zbar B, Toro J, et al. 2005. HIF overexpression correlates with biallelic loss of fumarate hydratase in renal cancer: Novel role of fumarate in regulation of HIF stability. Cancer Cell 8: 143-153.

Iyer NV, Kotch LE, Agani F, Leung SW, Laughner E, Wenger RH, Gassmann M, Gearhart JD, Lawler AM, Yu AY, et al 1998. Cellular and developmental control of $\mathrm{O}_{2}$ homeostasis by hypoxia-inducible factor $1 \alpha$. Genes Dev 12: 149-162.

Jain RK. 1988. Determinants of tumor blood flow: A review. Cancer Res 48: 2641-2658.

Kalas W, Swiderek E, Rapak A, Kopij M, Rak J, Strzadala L. 2011. H-ras up-regulates expression of BNIP3. Anticancer Res 31: 2869-2875.

Karantza-Wadsworth V, Patel S, Kravchuk O, Chen G, Mathew R, Jin S, White E. 2007. Autophagy mitigates metabolic stress and genome damage in mammary tumorigenesis. Genes Dev 21: $1621-1635$.

Klimova T, Chandel NS. 2008. Mitochondrial complex III regulates hypoxic activation of HIF. Cell Death Differ 15: 660666.

Komatsu M, Waguri S, Ueno T, Iwata J, Murata S, Tanida I, Ezaki J, Mizushima N, Ohsumi Y, Uchiyama Y, et al. 2005.
Impairment of starvation-induced and constitutive autophagy in Atg7-deficient mice. J Cell Biol 169: 425-434.

Kuma A, Mizushima N. 2010. Physiological role of autophagy as an intracellular recycling system: With an emphasis on nutrient metabolism. Semin Cell Dev Biol 21: 683-690.

Kuma A, Hatano M, Matsui M, Yamamoto A, Nakaya H, Yoshimori T, Ohsumi Y, Tokuhisa T, Mizushima N. 2004. The role of autophagy during the early neonatal starvation period. Nature 432: $1032-1036$.

Lock R, Roy S, Kenific CM, Su JS, Salas E, Ronen SM, Debnath J. 2011. Autophagy facilitates glycolysis during Ras-mediated oncogenic transformation. Mol Biol Cell 22: 165-178.

Lum JJ, Bauer DE, Kong M, Harris MH, Li C, Lindsten T, Thompson CB. 2005. Growth factor regulation of autophagy and cell survival in the absence of apoptosis. Cell 120: 237-248.

Manning BD, Cantley LC. 2007. AKT/PKB signaling: Navigating downstream. Cell 129: 1261-1274.

Mathew R, White E. 2011. Autophagy in tumorigenesis and energy metabolism: Friend by day, foe by night. Curr Opin Genet Dev 21: 113-119.

Mathew R, Karantza-Wadsworth V, White E. 2007a. Role of autophagy in cancer. Nat Rev Cancer 7: 961-967.

Mathew R, Kongara S, Beaudoin B, Karp CM, Bray K, Degenhardt K, Chen G, Jin S, White E. 2007b. Autophagy suppresses tumor progression by limiting chromosomal instability. Genes Dev 21: 1367-1381.

Mathew R, Karp CM, Beaudoin B, Vuong N, Chen G, Chen HY, Bray K, Reddy A, Bhanot G, Gelinas C, et al. 2009. Autophagy suppresses tumorigenesis through elimination of p62. Cell 137: $1062-1075$.

Maxwell PH, Wiesener MS, Chang GW, Clifford SC, Vaux EC, Cockman ME, Wykoff CC, Pugh CW, Maher ER, Ratcliffe PJ. 1999. The tumour suppressor protein VHL targets hypoxia-inducible factors for oxygen-dependent proteolysis. Nature 399: $271-275$.

Menon S, Manning BD. 2008. Common corruption of the mTOR signaling network in human tumors. Oncogene (suppl. 2) $27: \mathrm{S} 43-\mathrm{S} 51$.

Mizushima N. 2010. The role of the Atg1/ULK1 complex in autophagy regulation. Curr Opin Cell Biol 22: 132-139.

Mizushima N, Komatsu M. 2011. Autophagy: Renovation of cells and tissues. Cell 147: 728-741.

Mullen AR, Wheaton WW, Jin ES, Chen PH, Sullivan LB, Cheng T, Yang Y, Linehan WM, Chandel NS, DeBerardinis RJ. 2012. Reductive carboxylation supports growth in tumour cells with defective mitochondria. Nature 481: 385-388.

Neufeld TP. 2010. TOR-dependent control of autophagy: Biting the hand that feeds. Curr Opin Cell Biol 22: 157-168.

Ohh M, Park CW, Ivan M, Hoffman MA, Kim TY, Huang LE, Pavletich N, Chau V, Kaelin WG. 2000. Ubiquitination of hypoxia-inducible factor requires direct binding to the betadomain of the von Hippel-Lindau protein. Nat Cell Biol 2: 423-427.

Onodera J, Ohsumi Y. 2005. Autophagy is required for maintenance of amino acid levels and protein synthesis under nitrogen starvation. $J$ Biol Chem 280: 31582-31586.

Parsons DW, Jones S, Zhang X, Lin JC, Leary RJ, Angenendt P, Mankoo P, Carter H, Siu IM, Gallia GL, et al. 2008. An integrated genomic analysis of human glioblastoma multiforme. Science 321: 1807-1812.

Pollard PJ, Briere JJ, Alam NA, Barwell J, Barclay E, Wortham NC, Hunt T, Mitchell M, Olpin S, Moat SJ, et al. 2005. Accumulation of Krebs cycle intermediates and over-expression of HIF $1 \alpha$ in tumours which result from germline FH and SDH mutations. Hum Mol Genet 14: 2231-2239.

Pourova J, Kottova M, Voprsalova M, Pour M. 2010. Reactive oxygen and nitrogen species in normal physiological processes. Acta Physiol 198: 15-35.

Ramanathan A, Schreiber SL. 2009. Direct control of mitochondrial function by mTOR. Proc Natl Acad Sci 106: 2222922232.

Schieke SM, Phillips D, McCoy JP Jr, Aponte AM, Shen RF, Balaban RS, Finkel T. 2006. The mammalian target of 
rapamycin (mTOR) pathway regulates mitochondrial oxygen consumption and oxidative capacity. $J$ Biol Chem 281: $27643-27652$.

Semenza GL. 2010a. Defining the role of hypoxia-inducible factor 1 in cancer biology and therapeutics. Oncogene 29: $625-634$.

Semenza GL. 2010b. HIF-1: Upstream and downstream of cancer metabolism. Curr Opin Genet Dev 20: 51-56.

Shackelford DB, Shaw RJ. 2009. The LKB1-AMPK pathway: Metabolism and growth control in tumour suppression. Nat Rev Cancer 9: 563-575.

Sou YS, Waguri S, Iwata J, Ueno T, Fujimura T, Hara T, Sawada N, Yamada A, Mizushima N, Uchiyama Y, et al. 2008. The Atg8 conjugation system is indispensable for proper development of autophagic isolation membranes in mice. Mol Biol Cell 19: 4762-4775.

Suzuki SW, Onodera J, Ohsumi Y. 2011. Starvation induced cell death in autophagy-defective yeast mutants is caused by mitochondria dysfunction. PLoS One 6: e17412.

Talks KL, Turley H, Gatter KC, Maxwell PH, Pugh CW, Ratcliffe PJ, Harris AL. 2000. The expression and distribution of the hypoxia-inducible factors HIF- $1 \alpha$ and HIF- $2 \alpha$ in normal human tissues, cancers, and tumor-associated macrophages. Am J Pathol 157: 411-421.

White E, DiPaola RS. 2009. The double-edged sword of autophagy modulation in cancer. Clin Cancer Res 15: 5308-5316.

Wild P, Dikic I. 2010. Mitochondria get a Parkin' ticket. Nat Cell Biol 12: 104-106.

Wise DR, DeBerardinis RJ, Mancuso A, Sayed N, Zhang XY, Pfeiffer HK, Nissim I, Daikhin E, Yudkoff M, McMahon SB, et al. 2008. Myc regulates a transcriptional program that stimulates mitochondrial glutaminolysis and leads to glutamine addiction. Proc Natl Acad Sci 105: 18782-18787.

Yan H, Parsons DW, Jin G, McLendon R, Rasheed BA, Yuan W, Kos I, Batinic-Haberle I, Jones S, Riggins GJ, et al. 2009. IDH1 and IDH2 mutations in gliomas. New Engl J Med 360: $765-773$.

Yang S, Wang X, Contino G, Liesa M, Sahin E, Ying H, Bause A, Li Y, Stommel JM, Dell'antonio G, et al. 2011. Pancreatic cancers require autophagy for tumor growth. Genes Dev 25: 717-729.

Youle RJ, Narendra DP. 2011. Mechanisms of mitophagy. Nat Rev Mol Cell Biol 12: 9-14.

Zhang H, Gao P, Fukuda R, Kumar G, Krishnamachary B, Zeller KI, Dang CV, Semenza GL. 2007. HIF-1 inhibits mitochondrial biogenesis and cellular respiration in VHL-deficient renal cell carcinoma by repression of C-MYC activity. Cancer Cell 11: 407-420.

Zheng B, Jeong JH, Asara JM, Yuan YY, Granter SR, Chin L, Cantley LC. 2009. Oncogenic B-RAF negatively regulates the tumor suppressor LKB1 to promote melanoma cell proliferation. Mol Cell 33: 237-247.

Zhong H, De Marzo AM, Laughner E, Lim M, Hilton DA, Zagzag D, Buechler P, Isaacs WB, Semenza GL, Simons JW. 1999. Overexpression of hypoxia-inducible factor $1 \alpha$ in common human cancers and their metastases. Cancer Res 59: $5830-5835$.

Zoncu R, Efeyan A, Sabatini DM. 2011. mTOR: From growth signal integration to cancer, diabetes and ageing. Nat Rev Mol Cell Biol 12: 21-35. 


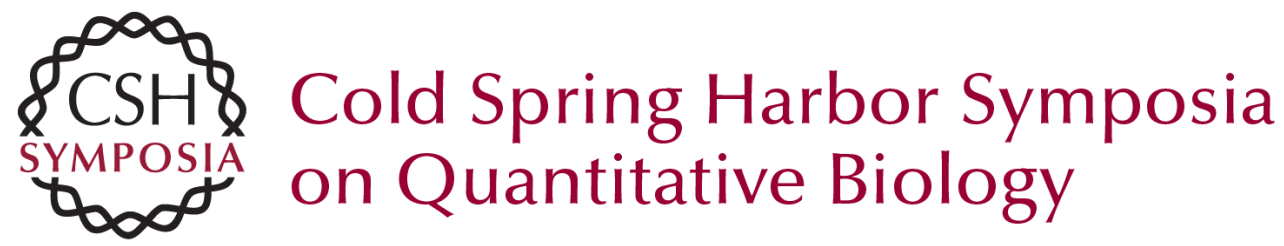

\section{Autophagy, Stress, and Cancer Metabolism: What Doesn't Kill You Makes You Stronger}

R. Mathew and E. White

Cold Spring Harb Symp Quant Biol 2011 76: 389-396 originally published online March 22, 2012 Access the most recent version at doi:10.1101/sqb.2012.76.011015

References This article cites 68 articles, 25 of which can be accessed free at: http://symposium.cshlp.org/content/76/389.full.html\#ref-list-1

License

Email Alerting Receive free email alerts when new articles cite this article - sign up in Service the box at the top right corner of the article or click here. 